\title{
MANUEL TOUSSAINT Y EL ARTE COLONIAL EN MEXICO
}

\author{
$\mathbf{P} \mathbf{O} \mathbf{R}$ \\ F R A N C ISCO DE I A M A Z A
}

WL Arte Colonial de México es tema nuevo en su historia. Se necesitó que llegara el fin del siglo XIx para que surgiese, tímidamente $y$ pidiendo permiso. Sin embargo, pronto dejó estos débiles comienzos para convertirse, hoy, en apasionado estudio dentro y fuera del pais y ocupar la atención de numerosos investigadores. EI historiador de la Historia del Arte de México en el futuro verá con admiración y asombro que, en tunas cuantas décadas, lo que antes era ignorancia, menosprecio o incertidumbre, es ahora fuente de enseñanza, de polémica, de crítica, de goce, $y$, en fin, de actividad cultural de primer orden.

Tratamos con fervor de conocernos a nosotros mismos y el estudio del Arte Colonial ha venido a mostrarnos una de nuestras facetas más importantes $y$ entrañables por su equilibrio ante sus dos orígenes inmediatos: el arte español y el arte indígena. Así han podido inutilizarse esas posiciones polares, paralíticas, que la pasión despertara peligrosamente al evocar y valorar solamente lo europeo o lo autóctono. En la clara armonía de la arquitectura, de la escultura, de las artes populares coloniales, el monocorde llamado de uno de los dos bandos queda aniquilado y en silencio ante el dúo flexible y veraz de la unión de las dos culturas, cuya expresión más auténtica, más inmediata y más palpable es el Arte Colonial. La simbiosis cultural de España y Anáhuac, más que en su Literatura, en su Jurisprudencia, en su Economia, en su Música, está en sus Artes Plásticas. El símbolo del México del pasado no 
es Teotihuacán; es la Catedral de Zacatecas; es Querétaro; el Carmen de San Luis; Oaxaca o Tonanzintla... Españoles, criollos, indios y mestizos dejaron el sello de trescientos años de fecunda historia en las piedras y en las maderas doradas más que en los poemas, los libros y las tesis doctorales de los siglos coloniales. No conocer la arquitectura colonial de México, la más importante de las manifestaciones artísticas de su pasado inmediato, es ignorar el más heroico esfuerzo por superarse, por ser-si-mismo, que haya logrado México antes de 1910. De aquí el mérito de quienes, como Manuel Toussaint, dedicaron su vida a esa labor admirable. Varios fueron los trazadores de esta nueva ruta de la cultura mexicana, y uno de los primeros, el más decidido y entusiasta, el más inteligente y mejor preparado, fué Manuel Toussaint. Encuadrar stı enorme actividad dentro de la historiografia del Arte Colonial y mostrar la deuda que tenemos con el maestro, es lo que pretendo en estas lineas, recordando, a grandes rasgos, la brecha que abrió su pluma en ese campo, antes de él casi infecundo $y$ ahora, gracias en mucho a él, repleto de buena cosecha.

La ignorancia del arte colonial durante el siglo xIx fué una obligación. Una obligación política. Habia que olvidar y aun odiar todo lo que recordara el imperio español. $Y$ esta actitud dimana desde nuestra petulante y mal redactada Acta de Independencia. $Y$ uno de los primeros decretos del Congreso fué mutilar casas e iglesias al raspar los escudos nobiliarios que las adornaban. Mas esto es perfectamente natural, como lo sería más tarde el destrozo de conventos. Todo régimen nuevo que se instaura destruye lo más que puede al anterior, que resulta su peor enemigo.

Desde la propia época colonial comienza el destrozo del Barroco con el estilo neoclásico, pero considerando que si políticamente aun eramos una colonia, no lo eramos ya culturalmente. El racionalismo neoclásico ya no es lo "colonial" en América, sino la incorporación a Europa en plan igualitario. Con el mismo afán con que España se entregó a la novedad intelectual de la Ilustración, México, que todo lo exageraba y lo engrandecía, no se quedó atrás y se sentó a la mesa de la Razón y de la restauración de lo clásico con los mismos alientos que inspiraron a España y Francia. Si España tuvo sus profetas antibarrocos en Ponz y en Jovellanos, México los logró en Alzate, Márquez y Fernández de 
Lizardi. Todos fueron contra el pasado y contribuyeron con eficacia a extender las nuevas ideas que arrasaron fachadas, retablos, rejas, muebles, que presentaban aspectos barrocos. "Montón de leña" llamó $E l$ Pensador Mexicano al Retablo de los Reyes, y Tolsá y Tresguerras dejaron casi limpias a las iglesias sustituyendo los retablos dorados por blancos altares de madera estilo neoclásico. Fué también la época de los ingenieros militares, quienes se apoderaron de cuantas obras de arquitectura se construían en América y España.

La independencia de las colonias exacerbó estos sentimientos y se miró todo lo español como un oprobio, a pesar de que se siguió con el neoclásico, pues no era posible crear de golpe nuevas formas, y así, en 1845 se construía la última obra de carácter "colonial", la cúpula de Santa Teresa, por el arquitecto español don Lorenzo de la Hidalga. Sin embargo, ese mismo año, el Cabildo Metropolitano destruía el bello y barroco ciprés de la Catedral, obra de Jerónimo de Balbás, del siglo xviı. Contradicciones casi todas inconcientes al proseguir con el neoclásico que, a pesar de su universalidad, era colonial y por otra parte, destruir at Barroco, es decir, lo más auténticamente nacional que hemos tenido. Sin saberlo y $\sin$ quererlo engendraban al Liberalismo, del cual se asustarian después y lo abominarían quienes racionalizaban las iglesias despojándolas de esa poderosa energía religiosa que entrañaba la lujosa decoración barroca. Malos tiempos para la comprensión del pasado colonial.

Resulta natural que fuese un extranjero, un italiano, el único que, pocos años después de la Independencia, se fijara en el Arte Colonial de México y lo describiera en algunas páginas entusiastas de su librito Le Mexique, publicado en París en 1831. No ha sido comentado ni traducido el libro del conde Beltrami y más bien ha sido visto con desdén por sus apresuradas $y$ superficiales observaciones, pero merece una nueva edición crítica por ser uno de los primeros dedicados a México apenas a los once años de su Independencia. Cuando menos no dice, como Humboldt, que el Sagrario de la ciudad de México es "gótico". Elogia desmesuradamente a Cabrera y su escuela y él es el primero que llama a Tresguerras "El Miguel Angel mexicano".

Después un silencio de varios años hasta la publicación del benemérito Diccionario de Historia y Geografia, iniciado en 1853 por varios intelectuales mexicanos de primera importancia en esa mitad del siglo. Alli se estudiaron muchos pintores, algunos escultores $y$ hasta varios edificios por un viejo conservador que no se dejó engañar por lo antiespañol, J. M. Dávila, quien se encargó, junto con don Manuel Orozco y Berra de 
lo concerniente a lo colonial. Sin embargo, hay que recordar que en este Diccionario se colaron mentiras y supercherías, como la del "primer" pintor colonial de México, Rodrigo de Cifuentes, que en un rato de buen humor inventó el siempre vivaz ingenio del Conde de la Cortina.

En 1861, año tormentoso y poco propicio, publicó don José Bernardo Couto, una de las más claras inteligencias del siglo xıx, el primer libro dedicado íntegramente a nuestro pasado artístico: el Diálogo de la Pintura en México, que reúne a sus vastos conocimientos el primer intento de crítica artística en México. Ha logrado esta obra dos ediciones más, la de Agüeros y la del Fondo de Cultura Económica, esta última con prólogo y notas de don Manuel Toussaint. "Si tuviéramos para la arquitectura algo equivalente a lo que el Diálogo es para la pintura - ha dicho Toussaint - la tarea del que pretende estudiar nuestros monumentos sería mucho más llevadera."

Estos primeros pasos se vieron completados por el libro de don Manuel G. Revilla El Arte en México, escrito en 1892 como contribución a los festejos del cuarto centenario del descubrimiento de América. Es un libro pequeño para tal tema y lleno de estrechez de criterio. Sin embargo, es el primero que lleva una nobilísima pretensión: estudiar en todo su conjunto el arte de México, desde el mundo prehispánico al moderno; "sería lo mismo que truncar la hisotria de las nobles artes el desdeñar y omitir el estudio de los palacios de Mitla, de las pinturas de los Juárez o de las estatuas de Tolsá", dice con toda razón. Por supuesto que todo el arte indigena, a pesar de que le parece que tiene "rasgos de belleza", no puede compararse, según Revilla, al gran arte clásico y es muy inferior a él. "Pero fué mucho lo que para su tiempo y su formación pudo ver Revilla, quien como historiador no podía prescindir de un trozo del pasado y en esto superó, concientemente, a Couto", ha dicho con acierto Justino Fernández.

Es en la parte dedicada a lo colonial, la más extensa, donde más faltas cometió el historiador de gabinete que fué don Manuel Revilla. Sin pretender menoscabar en lo más minimo el mérito indiscutible del ilustre maestro de la Escuela Nacional Preparatoria, recuerdo algunos detalles que no son culpa de él, sino de su época. Nos dice que los conquistadores y frailes no dejaron "suntuosas construcciones, tanto menos cuanto que no lo demandaban ni las exigencias de dominados ni las de los dominadores". Revilla ignoró los primitivos palacios de la ciudad de México que nos describe Cervantes de Salazar, a pesar de que don Joaquín García Icazbalceta habia ya publicado el México en 1554 ; él sólo la cita clavando 
los ojos en aquello de que "según su solidez cualquiera diría que no son casas, sino fortalezas" y se duele de que "no vemos entre los edificios aquí erigidos en el siglo XVI muestras del elegante estilo plateresco..." Bien se ve que nunca se dió una vuelta por Acolman y Yuriria ni se acordó de la casa de Montejo, en Mérida. Y con otra frase inexacta: "la más de las iglesias de entonces se construyeron con la cúpula característica del Renacimiento", despacha el siglo xvI, tratado en una treintena de lineas. Al hablar de la pintura colonial y referirse a Andrés de Concha cita las pinturas del retablo de Yanhuitlán y pone entre paréntesis: "(que aun deben de conservarse en su sitio)", pues sólo le constaba su existencia por la Crónica de Burgoa. Y de las pinturas de Cuauhtinchan supo gracias a José María Velasco, quien en sus excursiones poéticas en busca de paisajes sabia tener ojos para el pasado.

Pero con Revilla comienza también la rebelde queja contra el abandono, la incuria y la ignorancia que todavía padecemos en cuanto a conservación del Arte Colonial: "tan profundo es el indiferentismo sobre cosas de arte en el México de nuestros días, como grande fué el gusto que por las Bellas Artes aquí se tuvo durante los siglos virreinales", y lo que siempre será el mayor timbre de su gloria: la defensa, apasionada e inteligente del barroco del siglo xvIII, del "churrigueresco", con mayor y más hábil impulso que los críticos españoles de su tiempo, como Caveda, tan remisos y temerosos de contravenir la opinión general contra el Barroco.

Mucho tiene que agradecerle México a don Manuel Revilla por su ensayo de historia del arte, útil aun en varios aspectos a pesar de sus defectos. Su libro es el germen, humilde pero valioso, de la historia del arte en México, completa e insustituíble en muchos años, del Instituto de Investigaciones Estéticas de la Universidad Nacional de México con los nombres de Salvador Toscano, Manuel Toussaint y Justino Fernández.

En 1901 se inició el siglo para la historiografía artística con el libro del norteamericano Sylvester Baxter Spanish Colonial Architecture, traducido y publicado en 1934 por el departamente Bellas Artes. Baxter es un viajero, un turista observador e inteligente, pero vacío de cultura colonial, sin lecturas, sin libros, sin documentos. Sus capítulos son los lugares que visitó y así brinca de Tepozotlán a Puebla, de Valenciana a Taxco, para terminar con Cholula, sin plan alguno; sin embargo, la riqueza de sus ilustraciones, algunas opiniones atinadas y -en la segunda edición- las notas de Toussaint, hacen su obra imprescindible para el estudioso de Arte Colonial. 
Del hermoso libro de don Francisco Diez Barroso El Arte en Nueva España me basta recordar estas palabras de Toussaint: "pocas obras acerca de este asunto gozan de una presentación más seductora: excelente papel, grabados de primer orden, magnífica impresión hecha en los Estados Unidos... sin embargo, pocas obras serán más malas y perjudiciales que ésta, porque se ha acumulado tal cantidad de errores, so la capa de una teoría acerca de nuestro arte colonial, que aun personas dotadas de cierta cultura sufren la influencia de este libro y aceptan sus clasificaciones, toda vez que nadie las saca de su error."

Es a partir de 1915 cuando comienza la verdadera y magna obra de la historiografía del Arte Colonial y el nombre de Manuel Toussaint es el primicerio. Sin embargo, hay que recordar, con toda la importancia que se merece, el de don Manuel Romero de Terreros. Este ilustre historiador abarca todos los aspectos artísticos de la Colonia, sobre todo los más olvidados, como las llamadas Artes Menores: mobiliario, platería, tejidos, cerámica, etc., en nítidas monografías, como su bello libro Las Artes Industriales en la Nueva España, o formando conjuntos homogéneos como la serie de los tres tomitos de Arte Colonial o en numerosos artículos en las mejores revistas. Recuerdo que, recién salido de la imprenta el volumen del Arte Colonial de don Manuel Toussaint, le decía a Romero de Terreros: "Marqués, es usted el autor más citado en mi libro; puede convencerse viendo su papeleta del índice de nombres." La fecunda labor del marqués de San Francisco es insustituible. Lástima que esté tan dispersa y agotada; deberá reunirse un día cercano para que rindan mayor utilidad sus amplios conocimientos en historia y arte coloniales -o "virreinales", como él lo desea-.

Manuel Toussaint fué lo que se llama un "polígrafo". La palabra es fea pero nos señala su cualidad de escritor fecundo y variado, sin limitaciones, abierto a la cultura. Fué poeta y literato, crítico e historiador. historiador de ideas, de hechos, de detalles y de teorías; historiador de arte como cima y apogeo de sus desvelos y entusiasmos, pero igual sabía de novela que de teatro, de poesía que de filosofía del arte, de crítica literaria como de critica plástica. En Historia del arte conocia tan bien a los primitivos flamencos e italianos como a los pintores mexicanos del siglo XVI; a los renacentistas y barrocos españoles, italianos y franceses como a los nuestros de los siglos Xvir y Xvir. Sus vișiones, "alucinadas" 
de la arquitectura española no le quitaron calor a sus entusiasmos por nuestra arquitectura y si conocia tan admirablemente a España, Italia y Francia, no menos sabía de todos los rincones artísticos de México. No fué un investigador de gabinete. Fué el primer investigador viajero, no a la manera turística de Baxter, sino a la manera científica de Humboldt. "Manuel Toussaint -escribí sobre su libro Arte Colonial de México - ha ido directamente a los monumentos y obras de arte de la Nueva España con el espíritu nutrido de antemano en archivos y bibliotecas sin escatimar ningún sacrificio. En épocas en que no habia la facilidad de las carreteras y medios de comunicación actuales, se lanzaba al descubrimiento de viejos monasterios de los cuales sólo se sabía su existencia por algún párrafo o alguna línea de un viejo cronista. Viajaba en camiones desvencijados, a caballo, a pie, y llegaba a las iglesias y conventos del siglo xvi y luego nos regalaba, en libros y revistas, con una emotiva descripción ilustrada (cámara y gemelos siempre al hombro), el conocimiento de esas obras de arte perdidas en los ahora miserables pueblecitos de indios."

Su primer escrito de tema artístico no se publicó. Fué un ensayo, cargado de objeciones y duras críticas a la obra de Revilla. Con toda discreción, para no molestar al viejo maestro, lo guardó y permanece inédito. Gesto caballeroso el de Toussaint, pues la verdadera crítica se hace superando, como lo haría el mismo Toussaint con su obra posterior. Después articulos en revistas y su colaboración en la magna obra Iglesias de México, publicación de la Secretaría de Hacienda, en donde publicó su Arquitectura del siglo $X V I$ y la primera versión, por decirlo así, de $L a$ Catedral de México. Allí se ve ya al maduro y conciente investigador $y$ al fácil y magnífico escritor que aun no cumplía veintisiete años. En 1920 publica su libro Saturnino. Herrán y su obra, donde da a conocer a este artista, tan hijo de su época pero a la vez tan rebelde, primer conato de mexicanidad después del europeismo tan arraigado en la época porfiriana. Amigos fueron y de verdad; Herrán nos dejó un espléndido retrato de Toussaint, delgado, de grandes ojos dulces pero inquisitivos, nervioso e inteligente.

Sus viajes comenzaban a dar sus frutos. De 1926 es su pequeña monografía sobre Oaxaca, de la editorial "Cultura", honra tipográfica de su tiempo, y de 1931 la primera gran monografía en donde estudió esa entrañable $y$ maravillosa ciudad de Tasco. Es el primer estudio sobre una ciudad mexicana en donde se aunan el hitoriador sabio, el crítico entusiasta y el estilista cuidadoso. Método, descripciones, notas, texto, todo, 
en fin, hacen de este libro el modelo a seguir para monografías de ciudades, en donde no se escapa nada, desde la obra que define a Tasco: su imponderable parroquia de Santa Prisca, hasta detalles minuciosos de folklore y de vida cotidiana. A la vez se ocupa, con todo rigor crítico, a redactar los Catálogos de las pinturas de la Academia y prepara su Historia de la Pintura Colonial, que aun permanece inédita. Parte de este libro fué La Pintura en México durante el siglo XVI, publicada en la "Enciclopedia Ilustrada Mexicana", en 1936. Precisamente de este año parte la fundación del Instituto de Investigaciones Estéticas y la publicación de su revista, los Anales, que es la más nutrida, excelente y valiosa revista que sobre Arte de México ha producido nuestro país. En ella colaboró Toussaint en forma constante sobre los más variados temas artísticos de México, de tal manera que, el día que se reúnan en un volumen todos sus artículos y notas, resultará un libro de primera importancia para la historia del arte. Como lo es, justamente, el hermoso volumen de Paseos Coloniales, en donde nos lleva, en forma amena y a la vez sabiamente construída, a viejos conventos del siglo xvi, a la primitiva Catedral de México, a monumentos barrocos como Tepozotlán $y$ nos quedamos después de su lectura, aun sin quererlo, con un sólido y a la vez sabroso conocimiento de ciudades, pueblos y edificios como si hubiésemos estado en ellos.

En 1942 se publica la monografía sobre Pátzcuaro, que supera a la de Tasco en el cuidado que se puso en sus ilustraciones y la mayor amplitud de texto. Es también una obra exhaustiva sobre la preciosa ciudad michoacana.

Las formas artísticas nacionales resultaron estrechas para un tema que Toussaint conocía de maravilla: el arte mudéjar, por lo que traspasó las fronteras y escribió su Arte Mudéjar en América. Este tema, el americano total, lo tenían preparado y habían comenzado a escribirlo y publicarlo dos historiadores españoles de primer orden en Europa: don Diego Angulo Iñiguez y don Enrique Marco Dorta. Una contribución atinadísima fué este Arte Mudéjar en América, en plan comparativo entre las naciones que lo produjeron y que nos da un rico panorama de la influencia arábiga en nuestro continente.

Cuando en 1946 se quiso dar, por medio de un volumen, una idea de la cultura mexicana, el Gobierno publicó México y la Cultura, donde las plumas más prestigiadas nos dieron una visión de cada una de las especialidades científicas, literarias o artísticas que México habia fraguado en el devenir de su historia. Manuel Toussaint, naturalmente, fué 
el encargado de la historia del Arte Colonial, dejándonos un resumen que puede considerarse como libro de texto para los no especializados en la materia y como una necesaria guia para estudiantes y aficionados.

Para 1948 estaba reservada la producción cumbre y definitiva de Manuel Toussaint. Es el año en que publica sus dos obras monumentales: La Catedral de México y el Sagrario Metropolitano. Su Historia, su Tesoro, su Arte. Esta obra magna, para la cual consultó el archivo catedralicio en forma minuciosa y en la que colaboraron los mejores fotógrafos y grabadores del país, es otro ejemplo, otro modelo, de lo que puede y debe hacerse en monografías de arte. E1 templo máximo de América es estudiado parte por parte, con la completa historia de sus capillas, altares y obras de pintura, escultura y artes menores. Váse viendo su construcción trisecular con todo detalle, con la larga sucesión de arquitectura y artífices de todos órdenes, hasta su estado actual. Honra para el autor y para los editores, para la mitra primada de México, este libro espléndido es digno rival de los estudios que ha hecho Europa, amorosamente, de sus egregias catedrales. El otro gran volumen es el Arte Colonial de México, que completa la Historia del Arte en México que publicó este Instituto con la colaboración de Salvador Toscano para el Arte Precolombino y con la de Justino Fernández para el Arte Moderno y Contemporáneo.

Con este libro bastaría para dar a Manuel Toussaint la máxima categoría como historiador del Arte Colonial de México. Allí están reunidos y superados sus trabajos anteriores. Alli está el panorama completo del Arte Colonial, desde sus orígenes en manos de los primeros conquistadores y misioneros hasta la agonía del Barroco y la presencia del Neoclásico; allí está una teoría de la historia del arte en México que no es pertinente desarrollar aquí pero que es la pauta para los presentes y futuros historiadores del Arte en México.

Sin la generosa y laboriosa vida de Manuel Toussaint; sin sus incontables escritos sobre nuestro arte, lo más valedero que poseemos; sin su ejemplo como maestro y escritor, poco habríamos avanzado en esta hermosa obra de conocer nuestro pasado, es decir, de conocernos a nosotros mismos. En hombres como Manuel Toussaint pensaba Alfonso Reyes cuando escribió su aguda y certera frase: "Gracias a ellos no nos han reconquistado el desierto ni la maleza." 